\title{
ANALISIS PERBANDINGAN KOMPOSISI CAMPURAN BETON MUTU K-300 ANTARA BETON TANPA ADDITIVE DAN BETON MENGGUNAKAN ADDITIVE TIPE C MERK SIKACIM CONCRETE ADDITIVE DENGAN AGREGAT KASAR DESA SUNGAI DUA KABUPATEN TANAH BUMBU DAN AGREGAT HALUS DESA SUNGUP KABUPATEN KOTABARU KALIMANTAN SELATAN
}

\author{
Sylvina Permatasari \\ Prodi Teknik Sipil Politeknik Kotabaru \\ E-mail : sylvinapermata@gmail.com
}

\begin{abstract}
ABSTRAK
Penelitian dengan penambahan zat cair merk Sikacim Tipe C, dengan proses penambahan zat cair Sikacim yaitu dengan mencampurkan zat cair Sikacim ke dalam air. Material yang digunakan dalam pembuatan sampel beton ini berasal dari Kotabaru yaitu pasir diambil dari Desa Sungup dan kerikil dari Desa Sungai Dua Kabupaten Tanah Bumbu, air dari PDAM Kotabaru, semen Tiga Roda yang diproduksi oleh PT. Indocement Tunggal Prakasa, Tbk dan zat cair sikacim diproduksi oleh PT. Wibawa Putra Utama. Penelitian ini bertujuan untuk mengetahui karakteristik/spesifikasi dari material tersebut dengan tambahan zat cair sikacim. Untuk pelaksanaan penelitian ini menggunakan metode eksperimental di laboratorium. Mix design semen Tiga Roda, agregat halus Desa Sungup dan agregat kasar Desa Sungai Dua sesuai dengan mutu yang disyaratkan untuk $1 \mathrm{~m}^{3}$ beton adalah semen $454,86 \mathrm{~kg} / \mathrm{m}^{3}$, agregat halus Desa Sungup $608,6 \mathrm{~kg} / \mathrm{m}^{3}$, agregat kasar Desa Sungai Dua 993,2 kg/m $\mathrm{m}^{3}$ dan air sebanyak 218,33 Liter. Mix design semen Tiga Roda, agregat halus Desa Sungup, agregat kasar Desa Sungai Dua serta menggunakan additive tipe C merk Sikacim Concrete Additive sesuai dengan mutu yang disyaratkan untuk $1 \mathrm{~m}^{3}$ beton adalah semen 454,86 kg/m $\mathrm{m}^{3}$, agregat halus Desa Sungup 608,6 kg/m $\mathrm{m}^{3}$, agregat kasar Desa Sungai Dua 993,2 kg/m³ $, 174,67$ Liter dan zat additive sebanyak 272,91 ml.

Dari hasil penelitian mengenai jenis agregat halus Desa Sungup dan agregat Kasar Desa Sungai Dua terhadap kuat tekan beton antara beton tanpa additive dan beton yang menggunakan additive tipe $\mathrm{C}$ merk Sikacim Concrete Additive yaitu Mix design semen Tiga Roda, agregat halus Desa Sungup dan agregat kasar Desa Sungai Dua sesuai dengan mutu beton yang disyaratkan yaitu K-300 menghasilkan kuat tekan $300,30 \mathrm{~kg} / \mathrm{cm}^{2}$. Dari hasil pengujian sudah dapat memenuhi mutu yang direncanakan pada kuat tekan dan Mix design semen Tiga Roda, agregat halus Desa Sungup dan agregat kasar Desa Sungai Dua serta menggunakan additive tipe $\mathrm{C}$ merk Sikacim Concrete Additive sesuai dengan mutu beton yang disyaratkan yaitu K-300 menghasilkan kuat tekan $215,85 \mathrm{~kg} / \mathrm{cm}^{2}$. Dari hasil pengujian masih belum dapat memenuhi mutu beton yang direncanakan pada kuat tekan.
\end{abstract}

Kata Kunci : Beton, Additive tipe C merk Sikacim, Mutu Beton.

\section{PENDAHULUAN}

Beton merupakan suatu material yang secara harfiah merupakan bentuk dasar dari kehidupan sosial modern. Beton sendiri adalah merupakan campuran yang homogeny antara emen, air dan agregat. Karakteristik beton 
mempunyai tegangan hancur tekan yang tinggi serta tegangan hancur tarik yang rendah. Beton dihasilkan dari sekumpulan interaksi mekanis dan kimia sejumlah material pembentuknya. Semakin pesatnya perkembangan pembangunan dan banyaknya perubahan yang terjadi akibat aktivitas manusia yang semakin padat, maka semakin berkembang pula cara dan kualitas dari bangunan dan bahan-bahan yang dihasilkan, namun banyaknya jenis agregat yang digunakan dalam berbagai proyek serta dengan kualitas dan karakteristik yang berbeda-beda membuat kekuatan dan mutu beton kadang tidak sesuai dengan yang diharapkan.

Untuk pekerjaan yang berair atau untuk konstruksi yang memerlukan pengeringan yang cepat pelaksanaan sering menggunakan additive tipe $\mathrm{C}$ merk Sikacim Concrete Additive yang dikeluarkan oleh PT. Wibawa Putra Utama. Oleh karena itu penulis tertarik untuk melakukan penelitian menggunakan agregat kasar yang diambil di Desa Sungai Dua Kecamatan Simpang Empat Kabupaten Tanah Bumbu dan peneliti mengambil quary agregat halus di Desa Sungup Kabupaten Kotabaru serta melakukan perhitungan komposisi campuran beton mutu K-300 antara beton tanpa additive dan beton yang menggunakan additive tipe $\mathrm{C}$ merk Sikacim Concrete Additive.

\section{Tujuan dan Manfaat Penulisan}

1. Untuk menganalisis karakteristik agregat halus Desa Sungup Kabupaten Kotabaru dan agregat kasar Desa Sungai Dua Kabupaten Tanah Bumbu

2. Untuk menganalisis kuat tekan beton hasil mix design pada umur 28 hari dan untuk menganalisis perbandingan komposisi campuran beton mutu K300 antara beton tanpa additive dan beton yang menggunakan additive tipe C merk Sikacim Concrete Additive.

\section{TINJAUAN PUSTAKA}

Agregat adalah butiran mineral alami yang berfungsi sebagai bahan pengisi dalam campuran beton. Agregat ini menepati $70 \%$ - $75 \%$ dari total volume beton, maka kualitas agregat sangat memepengaruhi kualitas beton, tetapi sifat-sifat ini lebih bergantung pada faktor-faktor seperti bentuk dan ukuran butiran daripada jenis batunya. Akibatnya beton dalam jumlah besar dapat dibuat dari segala jenis batuan alamiah, nilai jumlah material cukup dan kualitas seragam berdasarkan ukuran butiran. Menurut SNI 1737-1989-F, agregat adalah sekumpulan butir-butir batu pecah, kerikil, pasir, atau mineral lainnya baik berupa hasil alam maupun hasil buatan. Agregat dapat dibedakan menjadi dua jenis, antara lain yaitu:

a. Agregat halus adalah agregat yang butirannya berkisar antara 0,15-5 mm dan semua butirannya menembus ayakan $4,8 \mathrm{~mm}(5 \mathrm{~mm})$, agregat ini biasanya disebut pasir.

b. Agregat kasar adalah agregat yang semua butirannya berkisar antara 5-40 $\mathrm{mm}$ dan semua butirannya tertinggal diatas ayakan $4,8 \mathrm{~mm}(5 \mathrm{~mm})$, agregat ini biasanya disebut kerikil.

\section{Perencanaan Mix Design}

Perencanaan mix design ini menggunakan metode DEO berdasarkan SK-SNI-T-15-1990-03. Dan adapun langkah-langkah dari mix design ini adalah sebagai berikut.

a. Menentukan kuat tekan karakteristik $\left(f c^{\prime}\right)$

Kuat tekan karakteristik yaitu kuat tekan yang disyaratkan pada umur tertentu, jumlah cacat tidak boleh lebih dari $5 \%$ artinya kekuatan yang ada hanya $5 \%$ yang diperbolehkan dari jumlah yang di test, dan perlu diketahui tentng nilai $\mathrm{fc}^{\prime}$ berarti kuat 
tekan beton dengan benda uji berbentuk silinder. Jika yang diketahui adalah nilai $\mathrm{K}$, maka nilai kuat tekan beton perlu dikonversi.

b. Deviasi standar

Deviasi standar di tetapkan berdasarkan tingkat mutu pengendalian pelaksanaan pencampuran betonnya, makin baik mutu pelaksanaan makin kecil nilai deviasi. Jika pelaksana tidak mempunyai data pengalaman atau mempunyai pengalaman kurang dari 15 buah benda uji, maka nilai deviasi standar diambil dari tingkat pengendalian mutu pekerjaan.

\section{METODE PENELITIAN}

\section{Pengujian kuat tekan beton}

Kuat tekan beton adalah besarnya beban persatuan luas yang menyebabkan benda uji hancur apabila dibebani dengan gaya tekan tertentu yang dihasilka oleh mesin tekan Compression Testing Machine Merk Control dengan kapasitas $120.000 \mathrm{~kg}$, dan adapun langkah-langkah pengujian adalah sebagai berikut:

a. Langkah-langkah pengujian

1) Bersihkan benda uji lalu timbang berapa beratnya

2) Benda uji diletakan pada mesin tekan secara sentris

3) Jalankan mesin tekan dengan penambahan beban yang konstan, terlihat jarum penunjuk pada manometer mesin tekan bergerak sesuai dengan besarnya pembebanan.

4) Pada beban maksimum yang mampu ditahan oleh kubus/silinder sudah terlampaui maka salah satu dari ujung penunjuk bergerak turun. Sedangkan jarum penunjuk lainnya menunjukan angka penekanan maksimum yaitu besarnya tegangan hancur dari benda uji tersebut dilakukan dengan perhitungan rumus.

Kuat tekan beton $: \sigma \mathrm{b}=\frac{P}{A}$
Dimana :

$\sigma_{\mathrm{b}} \quad=$ kuat tekan benda uji $\left(\mathrm{kg} / \mathrm{cm}^{2}\right)$

$P \quad=$ bahan maksimum $(\mathrm{kg})$

$A=$ luas penampang benda uji $\left(\mathrm{cm}^{3}\right)$

\section{Lokasi Penelitian}

Penelitian yang dilakukan meliputi pemeriksaan agregat halus, yaitu analisa saringan, pemeriksaan berat volume, pemeriksaan kadar organik, pemeriksaan kadar lumpur, pemeriksaan kadar air, analisa specific-gravity dan absorption, pemeriksaan keausan, pengujian slump dan campuran beton serta pengujian kuat tekan beton.

Pemeriksaan bahan ini bertujuan untuk mengetahui karakteristik agregat halus yang digunakan, serta menentukan apakah bahan memenuhi syarat untuk digunakan sebagai bahan campuran beton. Pemeriksaan ini dilakukan di Workshop Politeknik Kotabaru. Jl. Raya Stagen Km.8,5. Kotabaru.

\section{Data Penelitian}

Data yang dipakai adalah data primer, dimana agregat kasar dari Desa Sungai Dua Kecamatan Simpang Empat Kabupaten Tanah Bumbu dan agregat halus dari Desa Sungup Kecamatan Pulau Laut Tengah Kabupaten Kotabaru yang lamgsung diambil dari quary kemudian di teliti di laboratorium.

\section{HASIL PENELITIAN}

Untuk Analisa saringan agregat halus, dimana pemeriksaan ini dimaksudkan untuk menentukan pembagian atau distribusi butir (gradasi) agregat halus menggunakan saringan.

Tabel 1. Data Hasil Perhitungan Agregat Halus Desa Sungup

\begin{tabular}{cccc}
\hline & \multicolumn{3}{c}{ Pasir } \\
\cline { 2 - 4 } $\begin{array}{c}\text { Lubang } \\
(\mathrm{mm})\end{array}$ & $\begin{array}{c}\text { Berat } \\
\text { tertinggal }\end{array}$ & $\begin{array}{c}\text { Berat } \\
\text { persen } \\
\text { tertahan }\end{array}$ & $\begin{array}{c}\text { Persen } \\
\text { lolos }\end{array}$ \\
\cline { 2 - 4 } & gram & $\%$ & $\%$ \\
\hline
\end{tabular}




\begin{tabular}{cccc}
\hline No 12 & 15 & 1,50 & 98,50 \\
\hline No 16 & 31 & 4,60 & 95,40 \\
\hline No 30 & 217 & 26,30 & 73,70 \\
\hline No 50 & 293 & 55,60 & 44,40 \\
\hline No 100 & 338 & 89,40 & 10,60 \\
\hline PAN & 106 & 100,00 & 0,00 \\
\hline Total & 100 & &
\end{tabular}

harus ada perlakuan seperti pemecahan sampai berukuran maksimum $40 \mathrm{~mm}$, dan dari hasil pengujian menunjukan bahwa agregat kasar dari Desa Sungai Dua tidak termasuk dalam zona manapun seperti yang terlihat di dalam gambar 2 .

$\overline{\text { (Sylvina Permatasari, } 2021)}$

Dari Tabel 1 di atas dapat dapat dituangkan dalam grafik analisa saringan agregat halus dimana pasir di Desa Sungup menunjukan bahwa agregat halus dari Desa Parlin termasuk dalam gradasi zona II yang berarti pasir agak kasar.

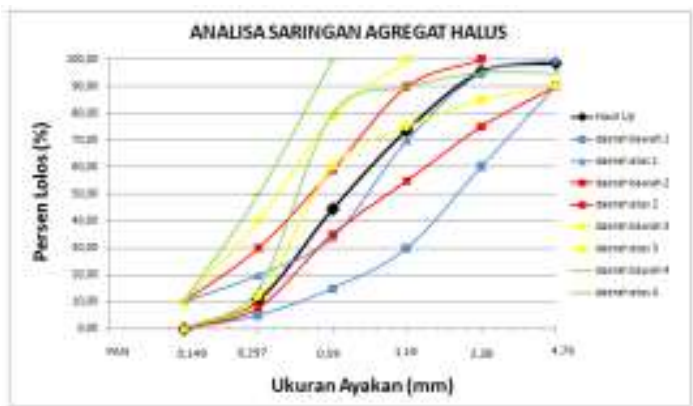

Gambar 1. Grafik Analisa Saringan Agregat Halus Desa Sungup

Tabel 2. Data Hasil Perhitungan Agregat Kasar Desa Sungai Dua

\begin{tabular}{|c|c|c|c}
\hline \multirow{2}{*}{$\begin{array}{c}\text { Lubang } \\
\text { ayakan } \\
(\mathrm{mm})\end{array}$} & \multicolumn{3}{|c}{ Kerikil } \\
\cline { 2 - 4 } & $\begin{array}{c}\text { Berat } \\
\text { tertinggal }\end{array}$ & $\begin{array}{c}\text { Berat } \\
\text { persen } \\
\text { tertahan }\end{array}$ & $\begin{array}{c}\text { Persen } \\
\text { lolos }\end{array}$ \\
\cline { 2 - 4 } & gram & $\%$ & $\%$ \\
\hline $11 / 2$ & 994 & 19.88 & 80.12 \\
\hline $1 / 4$ & 2.102 & 61.92 & 38.08 \\
\hline $1 / 2$ & 948 & 80.88 & 19.12 \\
\hline $3 / 8$ & 631 & 93.50 & 6.50 \\
\hline$\# 4$ & 177 & 97.04 & 2.96 \\
\hline PAN & 148 & 100.00 & 0.00 \\
\hline Total & 5.000 & & \\
\hline
\end{tabular}

(Sylvina Permatasari, 2021)

Dari Tabel 2 di atas dapat dapat dituangkan dalam grafik analisa saringan agregat kasar dimana kerikil di Desa Sungai Dua, pada analisa saringan ini untuk ukuran agregat kasar yang digunakan lebih dari $40 \mathrm{~mm}$ sehingga

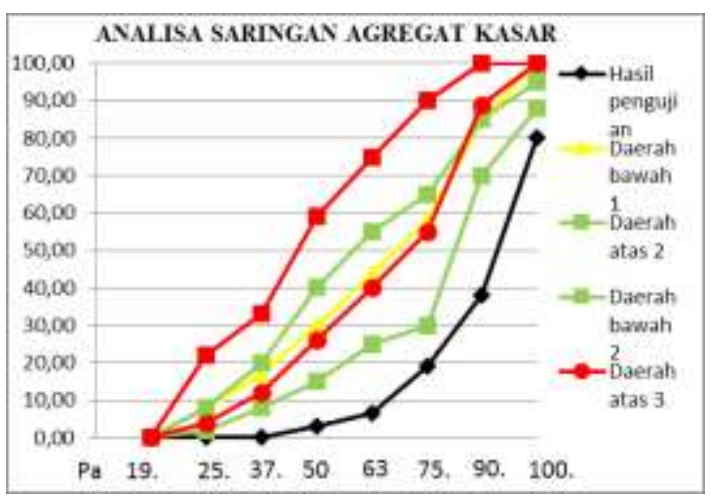

Gambar 2. Grafik Analisa Saringan

Agregat Kasar Desa Sungai Dua

Adapun mix design mutu K-300 dengan benda uji berbentuk silinder serta material-material yang digunakan yaitu Semen Tiga Roda, agregat kasar dari Desa Sungai Sungai Dua dan agregat halus dari Desa Sungup dapat dilihat pada Tabel 3.

Tabel 3. Mix Design K-300 Semen Tiga Roda, Pasir Desa Sungup dan Kerikil Desa Sungai Dua

\begin{tabular}{|c|c|c|}
\hline No & Uraian & Nilai \\
\hline 1 & $\begin{array}{l}\text { Kuat tekan yang } \\
\text { disyaratkan }\end{array}$ & $\begin{array}{l}24,9 \text { Mpa } \\
\text { pada } 28 \\
\text { hari bagian } \\
\text { cacat } 5 \%, \mathrm{k} \\
=1,64\end{array}$ \\
\hline 2 & Standar deviasi (s) & 7,0 MPa \\
\hline 3 & $\begin{array}{ll}\text { Nilai } & \text { tambah } \\
\text { (margin) } & \end{array}$ & $12 \mathrm{MPa}$ \\
\hline 4 & $\begin{array}{l}\text { Kekuatan rata-rata } \\
\text { yang ditargetkan }\end{array}$ & 29,1 MPa \\
\hline 5 & Jenis semen & Portland I \\
\hline 6 & Bahan tambah & $\begin{array}{l}\text { Sikacim } \\
\text { concrete } \\
\text { additive } \\
\text { tipe } \mathrm{C}\end{array}$ \\
\hline
\end{tabular}

7 Jenis agregat :

-Kasar Kerikil 


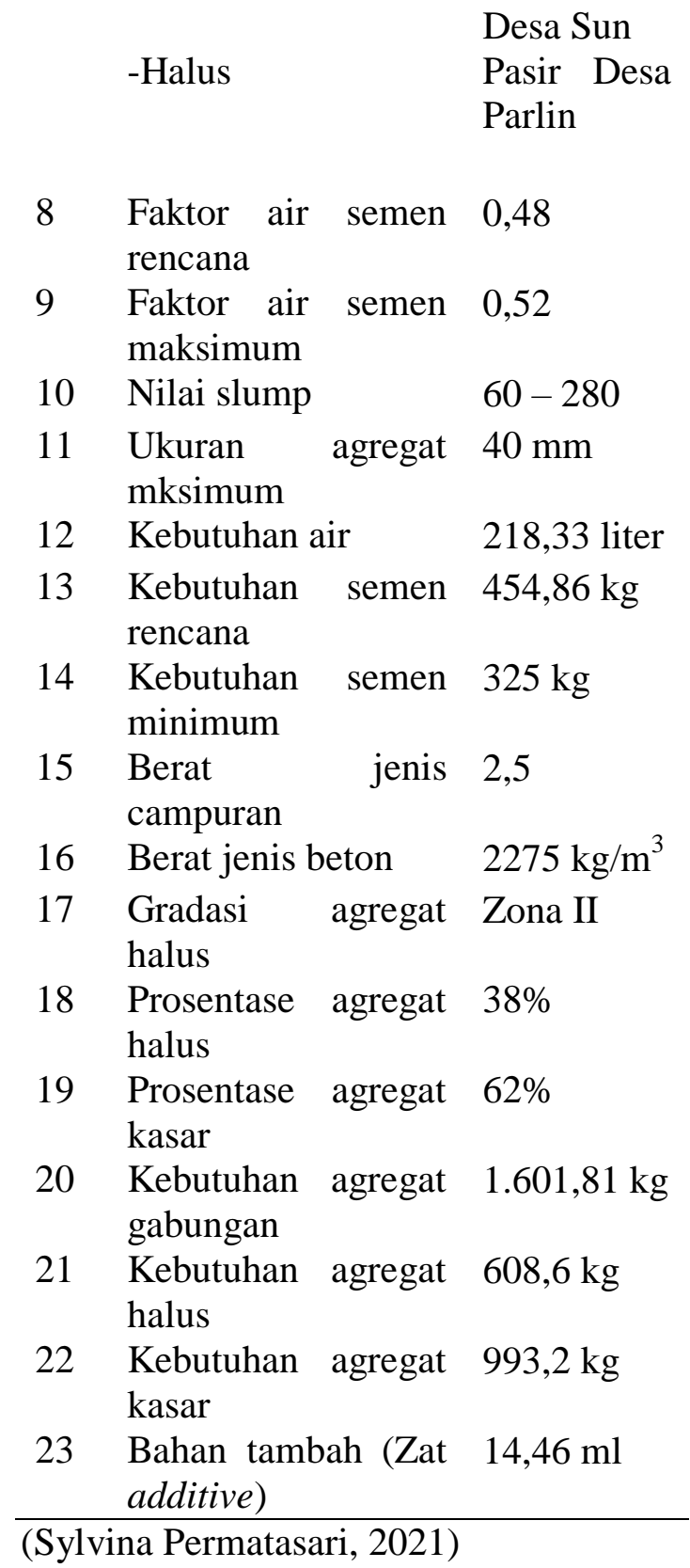

Hasil pemeriksaan bahan:

Dari hasil pemeriksaan bahan yang paling penting adalah kadar lumpur, kadar air, gradasi agregat dan abrasi pada agregat kasar, karena pemeriksaan ini menentukan apakah agregat halus dan agregat kasar tersebut dapat dipakai untuk bahan mix design. Adapun hasil pemeriksaan adalah sebagai berikut:

1) Pasir dari Desa Sungup mengandung kadar lumpur sebbesar 12,6\%, kadar air sebesar 4,38\%, dan analisa saringan termasuk dalam Zona II (pasir agak kasar)
2) Kerikil dari Desa Sungai Dua dari hasil abrasi sebesar 34,8\% < 40\% maka, agregat tersebut tahan terhadap daya tahan geser, kadar air sebesar $3,20 \%$ dan kadar lumpur sebesar 5\%.

a. Hasil pemeriksaan slump beton Pemeriksaan ini dimaksudkan untuk menentukan slump beton yang merupakan ukuran kekentalan beton segar, sehingga diketahui apakah adukan beton yang dibuat sudah memenuhi slump yang sudah ditentukan pada perhitungan sebelumnya. Adapun hasil pengujian slump pada pengujian ini adalah sebagai berikut.

1) Mix design semen Tiga Roda, agregat halus Desa Sungup dan agregat kasar Desa Sungai Dua, nilai slump adalah $8 \mathrm{~cm}$ untuk mutu beton K-300 (memenuhi syarat yang ditentukan)

2) Mix design semen Tiga Roda, agregat halus Desa Sungup dan agregat kasar Desa Sungai Dua serta menggunakan bahan tambah (additive), nilai slump adalah $10 \mathrm{~cm}$ untuk mutu beton $\mathrm{K}$ 300 (memenuhi syarat yang ditentukan)

b. Hasil perhitungan komposisi campuran

1) Mix design semen Tiga Roda, agregat halus Desa Sungup dan agregat kasar Desa Sungai Dua sesuai dengan mutu yang disyaratkan untuk $1 \mathrm{~m}^{3}$ beton adalah semen $454,86 \mathrm{~kg} / \mathrm{m}^{3}$, agregat halus Desa Sungup 608,6 kg/m ${ }^{3}$, agregat kasar Desa Sungai Dua 993,2 $\mathrm{kg} / \mathrm{m}^{3}$ dan air sebanyak 218,33 Liter.

2) Mix design semen Tiga Roda, agregat halus Desa Sungup, agregat kasar Desa Sungai Dua serta menggunakan additive tipe $\mathrm{C}$ merk Sikacim Concrete Additive sesuai dengan mutu yang disyaratkan untuk $1 \mathrm{~m}^{3}$ beton adalah semen $454,86 \mathrm{~kg} / \mathrm{m}^{3}$, agregat halus Desa Sungup 608,6 $\mathrm{kg} / \mathrm{m}^{3}$, agregat kasar Desa Sungai Dua 993,2 kg/m³ 174,67 Liter dan zat additive sebanyak $272,91 \mathrm{ml}$. 
Hasil pengujian kuat tekan berdasarkan hasil pengujian yang dilakukan, diperoleh hasil kuat tekan beton pada umur 28 hari.

Tabel 4. Konversi Kuat Tekan Beton Silinder

\begin{tabular}{l|l|l|l|l|l|l|l|l}
\hline $\begin{array}{l}\text { Umur beton } \\
\text { (hari) }\end{array}$ & 3 & 7 & 14 & 21 & 28 & 90 & 365 \\
\hline $\begin{array}{l}\text { Ke umur 28 } \\
\text { hari }\end{array}$ & 0,4 & 0,6 & 0,8 & 0,9 & 1,0 & 1,2 & 1,3 \\
5 & 8 & 5 & 0 & 0 & 5 \\
\hline
\end{tabular}

(Sylvina Permatasari, 2021)

Kuat tekan Silender usia 28 hari di konversi ke Kubus diambil angka 0.83 (PBI 1971)

Untuk benda uji I (Tanpa additive)

$$
\begin{aligned}
\sigma \mathrm{b} & =\frac{P}{A} \\
& =\frac{44.064}{176,79}=249,25 \mathrm{~kg} / \mathrm{cm}^{2}
\end{aligned}
$$

Diperoleh hasil pengujian sebesar 249,25 $\mathrm{kg} / \mathrm{cm}^{2}$

Untuk konversi mutu beton pada umur 28 hari dapat dihitung dengan rumus sebagai berikut.

$$
\left(\frac{\text { mutu beton umur } 28 \text { hari }}{\text { Faktor konversi ke umur } 28 \text { hari }}\right)
$$

Konversi bentuk sampel

$$
\left(\frac{249,25}{1,00}\right): 0,83=300,30 \mathrm{~kg} / \mathrm{cm}^{2}
$$

Didapatkan hasil dari 28 hari sebesar $300,30 \mathrm{~kg} / \mathrm{cm}^{2}$.

Jadi untuk benda uji I (Tanpa additive) dari hasil pengujian sudah dapat memenuhi mutu yang direncanakan pada kuat tekan.

Untuk benda uji II (menggunakan additive)

$$
\begin{aligned}
\sigma \mathrm{b} & =\frac{P}{A} \\
& =\frac{31,110}{176,79}=175,98 \mathrm{~kg} / \mathrm{cm}^{2}
\end{aligned}
$$

Diperoleh hasil pengujian sebesar 175,98 $\mathrm{kg} / \mathrm{cm}^{2}$
Untuk konversi mutu beton pada umur 28 hari dapat dihitung dengan rumus sebagai berikut.

$$
\left(\frac{\text { mutu beton umur } 28 \text { hari }}{\text { Faktor konversi ke umur } 28 \text { hari }}\right)
$$

Konversi bentuk sampel

$$
\left(\frac{175,98}{1,00}\right): 0,83=212,02 \mathrm{~kg} / \mathrm{cm}^{2}
$$

Didapatkan hasil dari 28 hari sebesar $212,02 \mathrm{~kg} / \mathrm{cm}^{2}$

Jadi untuk benda uji II (menggunakan additive) dari hasil pengujian belum dapat memenuhi mutu yang direncanakan pada kuat tekan.

Untuk benda uji III (menggunakan additive)

$$
\begin{aligned}
\sigma \mathrm{b} & =\frac{P}{A} \\
& =\frac{32,232}{176,79}=182,31 \mathrm{~kg} / \mathrm{cm}^{2}
\end{aligned}
$$

Diperoleh hasil pengujian sebesar 182,31 $\mathrm{kg} / \mathrm{cm}^{2}$

Untuk konversi mutu beton pada umur 28 hari dapat dihitung dengan rumus sebagai berikut.

$$
\left(\frac{\text { mutu beton umur } 28 \text { hari }}{\text { Faktor konversi ke umur } 28 \text { hari }}\right)
$$

Konversi bentuk sampel

$$
\left(\frac{182,31}{1,00}\right): 0,83=219,67 \mathrm{~kg} / \mathrm{cm}^{2}
$$

Jadi untuk benda uji III (menggunakan additive) dari hasil pengujian belum dapat memenuhi mutu yang direncanakan pada kuat tekan.

\section{KESIMPULAN}

Dari hasil penelitian mengenai jenis agregat halus Desa Sungup dan agregat Kasar Desa Sungai Dua terhadap kuat tekan beton antara beton tanpa additive 
dan beton yang menggunakan additive tipe C merk Sikacim Concrete Additive. dapat diambil kesimpulan berikut ini.

1. Mix design semen Tiga Roda, agregat halus Desa Sungup dan agregat kasar Desa Sungai Dua sesuai dengan mutu beton yang disyaratkan yaitu K-300 menghasilkan kuat tekan 300,30 $\mathrm{kg} / \mathrm{cm}^{2}$. Dari hasil pengujian sudah dapat memenuhi mutu yang direncanakan pada kuat tekan.

2. Mix design semen Tiga Roda, agregat halus Desa Sungup dan agregat kasar Desa Sungai Dua serta menggunakan additive tipe $\mathrm{C}$ merk Sikacim Concrete Additive sesuai dengan mutu beton yang disyaratkan yaitu K-300 menghasilkan kuat tekan 215,85 $\mathrm{kg} / \mathrm{cm}^{2}$. Dari hasil pengujian masih belum dapat memenuhi mutu beton yang direncanakan pada kuat tekan.

\section{DAFTAR PUSTAKA}

Das B.M..1994, Mekanika Tanah I dan II. Penerbit Erlangga.

Dwi Saputra, Andri, 2015, Pengaruh penambahan adiktif pada beton dengan campuran limbah batu bata, Politeknik Negeri Balikpapan.

Heri, 2013, Analisa Perbandingan Komposisi Campuran Beton Mutu K-300 dan Mutu K-225 Menggunakan Pasir Desa Sungup dan Kerikil Desa Sarang Tiung, Kotabaru, Politeknik Kotabaru.

Kurniawan, S. (2016). Analisa Perawatan Beton Cetak Menggunakan Uap. TAPAK (Teknologi Aplikasi Konstruksi): Jurnal Program Studi Teknik Sipil, 5(2).

Mulyono, Tri. (2004), Teknologi Beton, Yogyakarta.

PUBI. (1982). Persyaratan Umum Bahan Bangunan di Indonesia, Jakarta, Depdikbud.
Sumarni. (2014). Analisa Perbandingan Komposisi Campuran Beton MutuK-300 Menggunakan Agregat Dengan Gradasi Yang Berbeda Dari Desa Gunung Endek dan Kerikil Desa Sarang Tiung, Kotabaru, Politeknik Kotabaru.

SK-SNI-T15-1990-03, Tata Cara Pembuatan Rencana Beton Normal. Bandung, Yayasan LPMB.

SNI-03-2847-2002, Tata Cara Perhitungan Struktur Beton Untuk Bangunan Gedung, Bandung, Beta Version.

SK SNI S-04-1989-F, Spesifikasi Bahan Bangunan, Bandung, Yayasan LPMB.

Sumekto, Wuryati. dkk. (2001).Teknologi Beton. Yogyakarta, Kanisisus

Yanti, Lesti Erni. (2013). Analisa Karakteristik Agregat Kasar Desa Sarang Tiung dan Agregat Halus Desa Cantung Untuk Mendapatkan Mutu Beton K-250, $K-275, \quad K-300$ dan $K-350$, Kotabaru : Politeknik Kota. 